\title{
Poverty, Material Hardship, and Telomere Length Among Latina/o Children
}

\author{
Michael D. Niño ${ }^{1}$ \\ Received: 24 March 2021 / Revised: 20 May 2021 / Accepted: 24 May 2021 / Published online: 28 May 2021 \\ (C) W. Montague Cobb-NMA Health Institute 2021
}

\begin{abstract}
Background Despite increased attention on the links between poverty and the health and wellbeing of youth, few have attempted to understand the physiological consequences associated with different forms of economic disadvantage among Latina/o children. The present study begins to address this gap by (1) examining whether different forms of economic disadvantage were related to telomere length for Latina/o children and (2) determining whether parents' nativity shapes economic disadvantagetelomere length relationships.

Methods Data were drawn from the Fragile Families and Child Wellbeing Study, a longitudinal, stratified multistage probability sample of couples and children in 20 large US cities. The sample consisted of 417 Latina/o children and their parents that were followed from birth to age 9. Ordinary least squares regressions were used to examine relationships between economic disadvantage and telomere length.

Results Findings revealed that poverty status was not significantly related to telomere length, whereas some forms of material hardship were shown to play a role in the risk of premature cellular aging. More specifically, medical hardship and difficulty paying bills were associated with shorter telomere length at age 9. Results also provide minimal evidence economic disadvantage-telomere length patterns varied by parents' nativity. Only medical hardship was related to shorter telomere length at age 9 for children with at least one foreign-born parent.

Conclusion Overall, results indicate that the risk of premature cellular aging depends on the measure of economic disadvantage under investigation. Findings from this study can inform targeted strategies designed to reduce the deleterious consequences associated with economic deprivation.
\end{abstract}

Keywords Latina/o health $\cdot$ Material hardship $\cdot$ Telomere length $\cdot$ Nativity

\section{Introduction}

Latina/o children are the largest and fastest-growing historically marginalized racial and ethnic youth group in the USA. In states like California and Texas, Latina/os now also make up the numerical majority of students enrolled in public schools [1]. Although Latina/o children continue to fundamentally change racial and ethnic demographics in the USA, racialized social structures that have historically created unequal access to flexible resources (e.g., power, prestige, wealth, and social capital) [2] continue to place Latina/o children at a greater risk of living in poverty. For example,

Michael D. Niño

mnino@uark.edu

1 Department of Sociology and Criminology, University of Arkansas, Fayetteville, AR 72701, USA compared to White children, Latina/o children are approximately two and half times more likely to live below the poverty line [3] and, while Latina/o children comprise one-third of the general Latina/o population, approximately 4 out of 10 live in poverty [4].

The COVID-19 pandemic has also particularly impacted economic conditions for Latina/o families. From February 2020 to June 2020, the unemployment rate for Latina/os increased by more than $300 \%$, from 4.8 to $14.5 \%$, respectively [5]. With fewer economic and social resources, a growing number of Latina/o families report experiencing economic and health-related hardships. From August 2020 to December 2020, reports indicate that 29\% of Latina/o households with children experienced three or more co-occurring hardships (e.g., unemployment, food insecurity, poor physical health, behind on bills) due to the COVID-19 pandemic-nearly twice the rate of White households (16\%) [6]. 
The increasing number of Latina/o families experiencing poor economic conditions has the potential to shape long-term population health patterns for Latina/o children. While Latina mothers exhibit higher birthweights, better diets, and healthier prenatal behaviors [7-9], Latina/o children from lowerincome families exhibit poorer health $[10,11]$, experience delayed dental care [12], and have less access to health care $[13,14]$ when compared to their White counterparts. Similarly, other studies using less traditional measures of economic disadvantage find associations between different forms of material hardship and chronic health conditions $[15,16]$ and suboptimal health for children [11].

Given that economic deprivation exposes children to several environmental, social, and psychological stressors - such as family conflict, maternal depression, parental harshness, and diminished parental responsiveness [17-19]—a growing body of research seeks to understand how chronic stressors, such as economic disadvantage, can set into motion a series of physiological responses that accelerates the decline in physical functioning. Scholars theorize and have empirically demonstrated that being exposed to and having to cope with chronic stressors can set into motion a series of physiological responses that accelerates the decline in physical functioning, ultimately increasing the risk for disease susceptibility and early death [20-22]. Known as the weathering hypothesis $[20,23]$, this framework also emphasizes that inequities in chronic disease conditions among marginalized populations are due to a set of life experiences, social stressors, and access to resources that are markedly different from the general population.

When attempting to understand the physiological consequences of various chronic stress exposures, scholars have traditionally relied on the concept of allostatic load, which represents the "wear and tear" of regulatory systems when repeated allostatic responses are triggered due to prolonged stress exposure [24]. Scholars, however, find that biomarkers included in allostatic load measures vary greatly, are driven by data availability, and often cannot be compared across studies $[25,26]$. Given these limitations, researchers have turned to other biomeasures, such as telomere length, to understand the physiological consequences of chronic stress exposure.

Telomeres are protective DNA-protein structures on the ends of eukaryotic chromosomes that bind to DNA clusters and consist of simple sequences of telomeric DNA (TTAGGG) tandemly repeated at the end of each chromosome. When the cell divides, chromosome ends shorten with each chromosomal replication and cellular division. Once telomeres become critically shortened, active tumor suppressor genes are activated as a cellular defense mechanism, and the cell will enter into a state of senescence (arrest) and apoptosis (death). Telomere shortening generally occurs with advancing age in all somatic cells, including fibroblasts and leukocytes. Accumulating evidence suggests that exposure to stressors, such as chronic economic and social deprivation, can accelerate the shortening of telomeres [27-30]. Scholars theorize the frequent activation of the hypothalamus-pituitaryadrenal axis, sympathetic nervous system, and oxidative burden that potentially play a role in premature cellular aging [31]. Shortened telomeres are associated with a number of deleterious biological and physical consequences such as chromosome and genomic instability, inefficient mitosis, the onset of chronic health conditions, and premature death [32-37].

While there is a substantial body of scholarship theorizing the potential physiological consequences of economic deprivation on children, empirical evidence examining relationships between family economic conditions and biomeasures that capture the physiological consequences of stress is limited and often produces mixed results. For instance, Mitchell and colleagues [38] find the doubling of family-to-income needs ratio resulted in a 5\% increase in telomere length for Black boys. Other studies, however, find no association between income-based measures of poverty and telomere length for children [39-41]. To our knowledge, only one study has attempted to investigate the potential link between economic disadvantage and telomere length among Latina/o children. Using a representative sample of Mexican/Mexican-American children, Needham and colleagues [42] find no relation between poverty-to-income ratio and telomere length.

Given the inconsistency in findings and scarcity of research focusing on Latina/os, several questions about the potential physiological consequences of economic disadvantage for Latina/o children remain. First, to date, few have attempted to examine whether multiple measures of economic disadvantage shape telomere length patterns among Latina/o children. In general, the extant literature focuses on racial and ethnic differences in relationships between economic disadvantage and children's health, leaving questions about whether and how economic disadvantage shapes the risk of premature cellular aging within particular racial and ethnic groups. Second, while studies have assessed whether family income is associated with children's telomere length, little is known about the physiological consequences associated with different forms of economic disadvantage, such as material hardship. Third, most studies use cross-sectional data, hindering scholars' ability to capture cumulative stress exposures associated with economic disadvantage, potentially underestimating the role of chronic economic stressors on the premature cellular aging of children. Finally, due to a host of social and cultural mechanisms [43-45], there is evidence that Latina/o children with foreign parents exhibit fewer health risks when compared to children with US-born parents [11,46, 47], yet, little is known about whether nativity plays a role in relationships between measures of economic disadvantage and telomere length among Latina/o children. 
Using panel and genetic data from the Fragile Families and Child Wellbeing Study (FFCWS), the present study addresses these gaps by examining how multiple exposures to different forms of economic disadvantage are related to salivary telomere length. This research advances our understanding of whether and how forms of economic disadvantage (i.e., living below the poverty line, material hardship) shape the health of Latina/o children in three ways. First, while most research on Latina/o children's health use self-reports from parents [11, 48-50], the present study includes a measure of cellular aging, salivary telomere length, which is a reliable indicator of chronic stress exposure, disease susceptibility, and early mortality [51-53]. Utilizing this approach, the present study provides a deeper understanding of biological processes that might underlie associations between economic disadvantage and the health and wellbeing of Latina/o children.

Second, chronic exposure to various forms of economic disadvantage is likely to shape cellular aging patterns differently. For instance, a growing body of scholarship demonstrates that traditional income-based measures of poverty may be unable to accurately capture stressors tied to economic deprivation [54-56]. Studies also find while different forms of hardship are associated with one another; each type of hardship is best understood as arising from processes and structures that are not identical, resulting in potentially different levels of stress exposure [57]. For example, on the one hand, food insecurity may be experienced for a short period of time, may not be distributed equally across the family, and can improve or worsen with small changes in financial resources within a family unit. On the other hand, bill hardship may occur over a longer period of time (e.g., missed rent/mortgage payments), but once the consequences of nonpayment are initiated (e.g., loss of home), the entire family unit is impacted simultaneously. Taking advantage of the longitudinal nature of the FFCWS, the present study incorporates a measure that captures the number of times Latina/o children lived above the national poverty line in early childhood. Using different forms of material hardship as proximal measures of poverty, this study is also among the first to investigate whether premature cellular aging is associated with the number of exposures to types of material hardship for Latina/o children. Finally, as stated earlier, research documents parents' nativity plays an important role in the health and wellbeing of Latina/o children. Therefore, the role of parents' nativity in relationships between poverty status, material hardships, and telomere length was assessed.

\section{Data, Measures, and Method}

\section{Data}

Data for this study were drawn from the FFCWS, a longitudinal, stratified multistage probability sample of couples with children born between 1998 and 2000 in 20 large US cities. The FFCWS systematically oversampled for unmarried parents, but when weighted, is representative of US urban families and their children. Baseline interviews were conducted with mothers in the hospital within $24 \mathrm{~h}$ of their child's birth. When possible, fathers were interviewed in the hospital. If the father was not present, interviews were conducted in other locations shortly after the child's birth. Follow-up interviews were conducted with both parents when the child was 1,3,5, and 9 years old. At year 9 follow-up, mothers and their children provided saliva samples to enable biological assays of telomere length. Given that approximately $5 \%$ of all cases were missing, listwise deletion was used to obtain the final sample. More specifically, for inclusion in the final analytic sample, respondents must have had valid responses for all measures and valid sampling weights. The final analytic sample included 417 Latina/o children from 20 large US cities.

\section{Telomere Length}

Telomere length was measured using a quantitative real-time polymerase chain reaction (PCR) that produced absolute measurements in kilobases (see $\mathrm{S} 1$ for a detailed description of the PCR-based measure included in this study). Given that extreme values could represent mismeasurement or oral pathology, $1 \%$ of both tails were trimmed from the sample. Preliminary analyses indicated that the telomere length measure was positively skewed. Therefore, to approximate normal distribution, the telomere length measure was logtransformed.

\section{Material Hardship}

Material hardship measures, which assessed the ability to meet basic needs, focused on four domains: food insecurity, bill hardship, housing hardship, and medical hardship. To determine the cumulative risk of various forms of material hardship, measures captured exposure to material hardships from year 1 , year 3, and year 5 of the FFCWS. Final measures were summed to capture the number of times Latina/o children were exposed to particular hardships, ranging from 0 to 3 .

Food insecurity assessed whether, in the past 12 months, respondents received free food/meals or children went hungry because they could not afford more food.

Bill hardship captured whether respondents were exposed to at least one of the following bill-related hardships: inability to pay rent or mortgage; inability to pay gas, electric, or oil bill; had to borrow money to pay bills; had electricity turned off by utility company; and phone service disconnected because not enough money.

Housing hardship assessed whether respondents reported experiencing one of the following housing hardships: evicted from their homes or apartments; moved in with others because 
of financial problems; and stayed in a shelter, abandoned building, and/or car due to financial difficulty.

Medical hardship was defined as not having medical insurance at the time of the interview or having any household member forgo needed medical services due to financial cost.

\section{Poverty Status}

To measure poverty status, income-to-poverty ratios for each year were constructed, which is the ratio of household income divided by the income at the US poverty threshold for the given household size in the relevant year. Using this measure, children that lived in households with an income-to-poverty ratio above one were considered to be living above the poverty line, whereas scores at or below one were considered to be living at or below the poverty line. A final count measure was then created to capture the number of times a Latina/o child lived above the poverty line from year 1 , year 3 , and year 5 of the FFCWS. Similar to the other economic disadvantage measures, the final poverty status measure ranged from 0 to 3 .

\section{Covariates}

To test relationships between measures of economic disadvantage and telomere length for Latina/o children, the present study also included covariates - drawn from both maternal and paternal surveys - that are likely to be confounders. These measures include parents' nativity, maternal and paternal age and level of education, number of maternal biological children, family structure, maternal and paternal closeness to cultural heritage, maternal and paternal participation in cultural practices, and language use. All controls were derived from baseline and year 1 interviews. Maternal and paternal age were measured in years and ranged from ages 15 to 53 . Parents' nativity assessed whether either parent was born outside the USA (foreign born, US born). Maternal and paternal education was measured using four dummy variables: less than high school, high school or equivalent, some college, and college graduate (reference). The number of maternal biological children was derived from self-reports and ranged from 1 to 7. Family structure captured whether parents were living together at baseline. Closeness to cultural heritage measured agreement with the following statement: "I feel an attachment toward my own racial and ethnic heritage." Participation in cultural practices was measured using the following question "I participate in cultural practices of my own group, such as special food, music, or customs." Both measures ranged from (1) strongly agree to (4) strongly disagree. Language use was assessed using a binary measure that captured whether either parent preferred to be interviewed in Spanish at baseline.

\section{Statistical Methods}

Analyses included descriptive statistics of sample characteristics for the total sample and across parents' nativity. To assess whether there were significant differences in telomere length, measures of economic disadvantage, and other covariates by parents' nativity, tests of differences were included. Ordinary least squares regression models were then used to assess relationships between measures of economic disadvantage and telomere length for Latina/o children. The initial baseline model examines the relationship between poverty status and telomere length. Model 2 assesses whether different forms of material hardship play a role in premature cellular aging, net other controls. The final model includes all measures of economic disadvantage included in this study. All analyses adjusted for the clustered nature of the FFCWS at the city level. To account for the unequal probability of selection due to oversampling of non-martial births, all analyses were weighted using post-stratification weights [58]. Given that this study is focused on a subset of the FFCWS sample, Stata's subpop command was also used to ensure all cases were used in the calculation of standard errors [59]. Finally, collinearity diagnostics revealed that the variance inflation factors (VIFs) did not exceed the recommended value of 10 , suggesting there are no multicollinearity concerns among variables included in this study.

\section{Results}

Table 1 presents weighted descriptive statistics for the overall sample and by parent's nativity. The majority of the final analytic sample was male (57\%) and had a least one parent born outside the USA (57\%). Approximately half of Latina/o children had fathers (49\%) and mothers (52\%) with less than a high school education or equivalent, and less than one-third (32\%) were living with both parents at the time of baseline interviews. With respect to poverty status, the number of times Latina/o children lived above the poverty line was, on average, 1.7. In other words, Latina/o children lived above the poverty line close to two of the 3 years poverty status was assessed. Results also show that the average poverty status score was significantly higher for children with two US parents when compared to having at least one foreign-born parent. Shifting to material hardship, being able to pay bills on time was the most prevalent reported type of hardship. More specifically, from year 1 to year 5, mothers reported being unable to pay bills on time, on average, 1.63 times. Results also demonstrate that, on average, mothers reported experiencing the remaining hardships less than once (medical hardship $(m=.49)$, food insecurity $(m=.36)$, and housing hardship $(m=.23))$ from years 1 to 5 . Latina/o children with at least one foreign-born parent also had significantly higher exposure 
Table 1 Weighted descriptive statistics for all study variables

\begin{tabular}{|c|c|c|c|}
\hline & $\begin{array}{l}\text { Overall } \\
\text { Mean (SD) [range] }\end{array}$ & $\begin{array}{l}\text { US-born parent } \\
\text { Mean (SD) [range] }\end{array}$ & $\begin{array}{l}\text { Foreign-born parent } \\
\text { Mean (SD) [range] }\end{array}$ \\
\hline \multicolumn{4}{|l|}{ Telomere length } \\
\hline Average telomere length (ln) & $\begin{array}{l}2.05(.03) \\
\quad[1.32-2.79]\end{array}$ & $\begin{array}{l}2.02(.04) \\
\quad[1.32-2.69]\end{array}$ & $2.07(.03)[1.34-2.79]$ \\
\hline \multicolumn{4}{|l|}{ Dimension of material hardship } \\
\hline Food insecurity & $0.36(.10)[0-3]$ & $0.24(.08)[0-3]$ & $0.45(.16)^{* * *}[0-3]$ \\
\hline Bill hardship & $1.63(.16)[0-3]$ & $1.60(.20)[0-3]$ & $1.64(.23)[0-3]$ \\
\hline Housing hardship & $0.23(.05)[0-3]$ & $0.27(.05)[0-3]$ & $0.21(.08)[0-3]$ \\
\hline Medical hardship & $0.49(.08)[0-3]$ & $0.44(.08)[0-3]$ & $0.53(.14)[0-3]$ \\
\hline Poverty Status & $1.72(.55)[0-12.10]$ & $2.13(.12)[0-12.10]$ & $\begin{array}{c}1.40(.20)^{* * * *} \\
{[0-11.39]}\end{array}$ \\
\hline \multicolumn{4}{|l|}{ Parent nativity } \\
\hline Parent foreign born & $0.57(.05)[0-1]$ & & \\
\hline \multicolumn{4}{|l|}{ Assigned gender at birth } \\
\hline Female & $0.43(.06)[0-1]$ & $0.47(.06)[0-1]$ & $0.41(.08)[0-1]$ \\
\hline \multicolumn{4}{|l|}{ Parent age } \\
\hline Mother age & $25.97(.59)[15-43]$ & $24.24(.58)[15-43]$ & $\begin{array}{c}27.27(.87)^{* * * *} \\
{[16-42]}\end{array}$ \\
\hline Father age & $27.74(.62)[16-53]$ & $26.05(.52)[16-47]$ & $\begin{array}{l}29.01(.98)^{* * * *} \\
{[18-53]}\end{array}$ \\
\hline \multicolumn{4}{|l|}{ Mother education } \\
\hline$<$ high school & $0.52(.06)[0-1]$ & $0.35(.06)[0-1]$ & $0.64(.08)^{* * *}[0-1]$ \\
\hline High school or equivalent & $0.25(.05)[0-1]$ & $0.33(.06)[0-1]$ & $0.19(.06)[0-1]$ \\
\hline Some college & $0.20(.04)[0-1]$ & $0.28(.05)[0-1]$ & $0.14(.05)[0-1]$ \\
\hline College graduate & $0.03(.01)[0-1]$ & $0.04(.02)[0-1]$ & $0.03(.02)[0-1]$ \\
\hline \multicolumn{4}{|l|}{ Father education } \\
\hline$<$ high school & $0.49(.06)[0-1]$ & $0.27(.05)[0-1]$ & $0.65(.08)^{* * *}[0-1]$ \\
\hline High school or equivalent & $0.26(.04)[0-1]$ & $0.37(.06)[0-1]$ & $0.17(.06)[0-1]$ \\
\hline Some college & $0.21(.04)[0-1]$ & $0.31(.07)[0-1]$ & $0.13(.04)[0-1]$ \\
\hline College graduate & $0.04(.02)[0-1]$ & $0.04(.02)[0-1]$ & $0.05(.03)[0-1]$ \\
\hline \multicolumn{4}{|l|}{ Other controls } \\
\hline Number of children & $1.45(.09)[1-7]$ & $1.37(.10)[1-5]$ & $1.51(.13)+[1-7]$ \\
\hline Cohabitating baseline & $0.32(.05)[0-1]$ & $0.45(.06)[0-1]$ & $0.22(.05)^{* * *}[0-1]$ \\
\hline Mother closeness to cultural heritage & $2.16(.11)[1-4]$ & $1.87(.17)[1-4]$ & $2.44(.13)^{* * *}[1-4]$ \\
\hline $\begin{array}{l}\text { Mother' participation in cultural } \\
\text { practices }\end{array}$ & $2.23(.10)[1-4]$ & $1.95(.14)[1-4]$ & $2.39(.12)[1-4]$ \\
\hline $\begin{array}{l}\text { Father participation in cultural } \\
\text { practices }\end{array}$ & $2.23(.10)[1-4]$ & $1.99(.12)[1-4]$ & $2.42(.14)^{* * *}[1-4]$ \\
\hline Father closeness to cultural heritage & $2.00(.10)[1-4]$ & $2.09(.09)[1-4]$ & $1.94(.16)[1-4]$ \\
\hline \multirow[t]{2}{*}{ Interview in Spanish } & $0.45(.06)[0-1]$ & $0.00(.00)[0-1]$ & $0.79(.07)[0-1]$ \\
\hline & $n=417$ & $n=244$ & $n=173$ \\
\hline
\end{tabular}

Note: $p$ values were derived from $t$ tests for continuous measures and $\chi^{2}$ tests for categorical measures

Ln natural logarithm

$+\mathrm{p}<0.10$

$* \mathrm{p}<.05$

$* * \mathrm{p}<.01$

$* * * \mathrm{p}<.001$

to food insecurity when compared to Latina/o children with two US-born parents. Finally, results from Table 1 show children with at least one foreign-born parent had mothers with significantly higher attachment to their cultural heritage, whereas fathers were more likely to participate in cultural practices when compared to children with two US-born parents. 
Table 2 provides OLS estimates for associations between poverty status, forms of material hardship, and telomere length for Latina/o children. Estimates from model 1 in Table 3 reveal that poverty status was not significantly associated $(b=.01, p=.97$ ) with telomere length for Latina/o children. Shifting to model 2 , results demonstrate that some forms of material hardship were significantly associated with premature cellular aging. For instance, greater exposure to bill hardship from years 1 to 5 was associated with shorter telomere length at year $9(b=-.05, p=.02)$. Similarly, Table 2 also shows shorter telomere length at age 9 for Latina/o children that experienced greater exposure to medical hardship from year 1 to year $5(b=-.07, p=.000)$. Results from model 3 , the fully adjusted model, reveal poverty status, and measures of material hardship maintain their associations with telomere length, net controls. To better illustrate observed patterns from model 3, Fig. 1 presents the predicted average telomere length for each economic disadvantage measure, holding control variables at their observed values. Results show the average telomere length shortened from $8.91 \mathrm{kbp}$ for children that were not exposed to bill hardships to 7.41 $\mathrm{kbp}$ for children that had been experienced bill hardship from years 1 to 5. Similarly, the average telomere length for children with no reported medical hardship was $8.56 \mathrm{kbp}$, whereas
Table 2 OLS regression estimates predicting log telomere length from income-based poverty, material hardships, and other covariates

\begin{tabular}{|c|c|c|c|}
\hline Constant & $\begin{array}{l}\text { Model } 1 \\
1.86(.18)^{* * *}\end{array}$ & $\begin{array}{l}\text { Model } 2 \\
1.96(.19)^{* * * *}\end{array}$ & $\begin{array}{l}\text { Model } 3 \\
1.96(.18)^{* * *}\end{array}$ \\
\hline \multicolumn{4}{|l|}{ Economic disadvantage } \\
\hline Poverty status & $.01(.02)$ & & $.00(.02)$ \\
\hline Food insecurity & & $.02(.02)$ & $.02(.02)$ \\
\hline Bill hardship & & $-.05(.02)^{*}$ & $-.05(.02)^{*}$ \\
\hline Housing hardship & & $-.00(.04)$ & $.01(.04)$ \\
\hline Medical hardship & & $-.07(.02) * * *$ & $-.07(.02)^{* * *}$ \\
\hline \multicolumn{4}{|l|}{ Parent nativity } \\
\hline Foreign born & $-.09(.10)$ & $-.11(.10)$ & $-.11(.10)$ \\
\hline \multicolumn{4}{|l|}{ Assigned gender at birth } \\
\hline Female & $.07(.06)$ & $.10(.05)+$ & $.10(.05)+$ \\
\hline \multicolumn{4}{|l|}{ Parent age } \\
\hline Mother age & $.00(.01)$ & $.00(.01)$ & $.00(.01)$ \\
\hline Father age & $.01(.00)$ & $.00(.00)$ & $.00(.00)$ \\
\hline \multicolumn{4}{|l|}{ Mother education } \\
\hline High school or equivalent & $.11(.08)$ & $.11(.07)$ & $.11(.07)$ \\
\hline Some college & $.00(.07)$ & $.04(.07)$ & $.03(.07)$ \\
\hline College graduate & $.00(.11)$ & $.05(.11)$ & $.05(.11)$ \\
\hline \multicolumn{4}{|l|}{ Father education } \\
\hline High school or equivalent & $.00(.06)$ & $.01(.06)$ & $.01(.06)$ \\
\hline Some college & $.12(.08)$ & $.10(.07)$ & $.09(.06)$ \\
\hline College graduate & $.15(.09)$ & $.11(.09)$ & $.10(.10)$ \\
\hline \multicolumn{4}{|l|}{ Other controls } \\
\hline Number of children & $.01(.02)$ & $.01(.02)$ & $.01(.02)$ \\
\hline Interview in Spanish & $.19(.08)^{*}$ & $.24(.07)^{* *}$ & $.25(.07)^{* *}$ \\
\hline Cohabitating baseline & $-.01(.04)$ & $-.00(.04)$ & $.00(.04)$ \\
\hline Mother closeness to cultural heritage & $.03(.02)$ & $.04(.02)$ & $.04(.02)$ \\
\hline Mother participation in cultural practices & $.00(.02)$ & $.00(.02)$ & $.00(.02)$ \\
\hline Father participation in cultural practices & $.03(.03)$ & $.00(.02)$ & $.00(.02)$ \\
\hline \multirow[t]{2}{*}{ Father closeness to cultural heritage } & $.00(.02)$ & $.00(.02)$ & $.00(.02)$ \\
\hline & $n=417$ & $n=417$ & $n=417$ \\
\hline \multicolumn{4}{|l|}{$+\mathrm{p}<0.10$} \\
\hline \multicolumn{4}{|l|}{$* \mathrm{p}<.05$} \\
\hline \multicolumn{4}{|l|}{$* * \mathrm{p}<.01$} \\
\hline$* * * \mathrm{p}<.001$ & & & \\
\hline
\end{tabular}


Table 3 OLS regression estimates predicting log telomere length from income-based poverty, material hardships, and other covariates by parent nativity

\begin{tabular}{|c|c|c|}
\hline Constant & $\begin{array}{l}\text { Foreign born } \\
1.91(.20)^{* * *}\end{array}$ & $\begin{array}{l}\text { US born } \\
1.86(.15)^{* * *}\end{array}$ \\
\hline \multicolumn{3}{|l|}{ Economic disadvantage } \\
\hline Food insecurity & $-.01(.03)$ & $-.03(.08)$ \\
\hline Bill hardship & $.06(.03)$ & $-.03(.03)$ \\
\hline Housing hardship & $-.06(.06)$ & $.04(.04)$ \\
\hline Medical hardship & $-.10(.02)^{* * *}$ & $-.05(.03)+$ \\
\hline Poverty status & $-.01(.03)$ & $.02(.03)$ \\
\hline \multicolumn{3}{|l|}{ Assigned gender at birth } \\
\hline Female & $.08(.05)$ & $.08(.08)$ \\
\hline \multicolumn{3}{|l|}{ Parent age } \\
\hline Mother age & $.00(.00)$ & $-.01(.01)$ \\
\hline Father age & $.01(.01)$ & $.01(.00)$ \\
\hline \multicolumn{3}{|l|}{ Mother education } \\
\hline High school or equivalent & $.11(.11)$ & $.12(.09)$ \\
\hline Some college & $-.01(.11)$ & $.11(.07)$ \\
\hline College graduate & $-.00(.13)$ & $.24(.18)$ \\
\hline \multicolumn{3}{|l|}{ Father education } \\
\hline High school or equivalent & $-.01(.09)$ & $.03(.05)$ \\
\hline Some college & $.18(.09)+$ & $.08(.10)$ \\
\hline College graduate & $.18(.06)^{* *}$ & $-.03(.18)$ \\
\hline \multicolumn{3}{|l|}{ Other controls } \\
\hline Number of children & $.01(.03)$ & $.01(.05)$ \\
\hline Interview in Spanish & $.18(.08)^{*}$ & $-.02(.13)$ \\
\hline Cohabitating baseline & $-.02(.06)$ & $-.04(.08)$ \\
\hline Mother closeness to cultural heritage & $.06(.03)$ & $.00(.03)$ \\
\hline Mother participation in cultural practices & $.00(.03)$ & $-.01(.02)$ \\
\hline Father participation in cultural practices & $.06(.03)+$ & $-.02(.03)$ \\
\hline \multirow[t]{2}{*}{ Father closeness to cultural heritage } & $.04(.03)$ & $-.05(.04)$ \\
\hline & $N=173$ & $N=244$ \\
\hline
\end{tabular}

$+\mathrm{p}<0.10$

$* \mathrm{p}<.05$

$* * \mathrm{p}<.01$

$* * * \mathrm{p}<.001$

the average telomere length for children with three reported medical hardships was $6.97 \mathrm{kbp}$, respectively. Finally, the remaining measures of economic disadvantage - poverty status, food insecurity, and housing hardship — were not significantly associated with telomere length for Latina/o children at age 9.

Table 3 assessed whether parents' nativity played a significant role in relationships between economic disadvantage and telomere length among Latina/o children. Results show that there is minimal evidence to support the notion that nativity shapes economic disadvantage-telomere length relationships with one exception. With respect to medical hardship, an increased number of exposures decreased average telomere length $(b=-.10, p=.000)$ for Latina/o children with at least one foreign-born parent. More specifically, Fig. 2 shows that the average telomere length for Latina/o children with at least one foreign-born parent with no reported medical hardships was $7.75 \mathrm{kbp}$, but for children with three reported medical hardships, average telomere length was reduced to $5.56 \mathrm{kbp}^{1}$.

\section{Discussion}

The purpose of this study was two-fold. First is to assess whether poverty status and different forms of material hardship (i.e., food insecurity, bill hardship, housing hardship, medical hardship) in early childhood were significantly associated with telomere length for Latina/o children at age 9. A growing body of evidence also suggests that parents' nativity may shape health risk profiles of Latina/o children. Therefore, the present study also assessed whether economic disadvantage-telomere length patterns varied across parents' nativity.

Using genetic and survey data from the Fragile Families and Child Wellbeing Study, results demonstrate only some forms of economic disadvantage related to premature cellular aging for Latina/o children. More specifically, results indicated that poverty status was not significantly related to telomere length for Latina/o children. These findings are consistent with scholarship that demonstrates traditional income-based measures of poverty may be unable to accurately capture stressors tied to economic deprivation [54-56]. Absolute measures of economic deprivation, such as income-based poverty status, have been used to understand the consequences of poverty in the USA since the 1960s. Developed by Orshansky [60], the federal poverty threshold is operationalized using the cost of a minimum diet, which is then multiplied by three to account for expenses with other goods and services. Poverty thresholds are updated yearly using the Consumer Price Index (CPI) and vary by family size and age of members living in a given household. In the late twentieth Century, economic deprivation scholarship began to show that the use of absolute measures of poverty may be unable to capture whether families can meet basic needs [61, 62]. At the time, people were spending closer to one-seventh of their income on food, as opposed to one-third. Poverty measurements also do not consider the value of noncash transfers (i.e., housing subsidies), obscuring the amount of gross cash income families have at their disposal.

\footnotetext{
${ }^{1}$ To generate predicted values for Fig. 2, children with at least one foreignborn parent and children with US-born parents were included in the models together with an interaction between medical hardship and parent nativity. This strategy makes it possible to hold all additional variable constant at their overall mean but assumes the effects of the other predictors are equal across nativity categories.
} 
Fig. 1 Average TL across forms of economic disadvantage

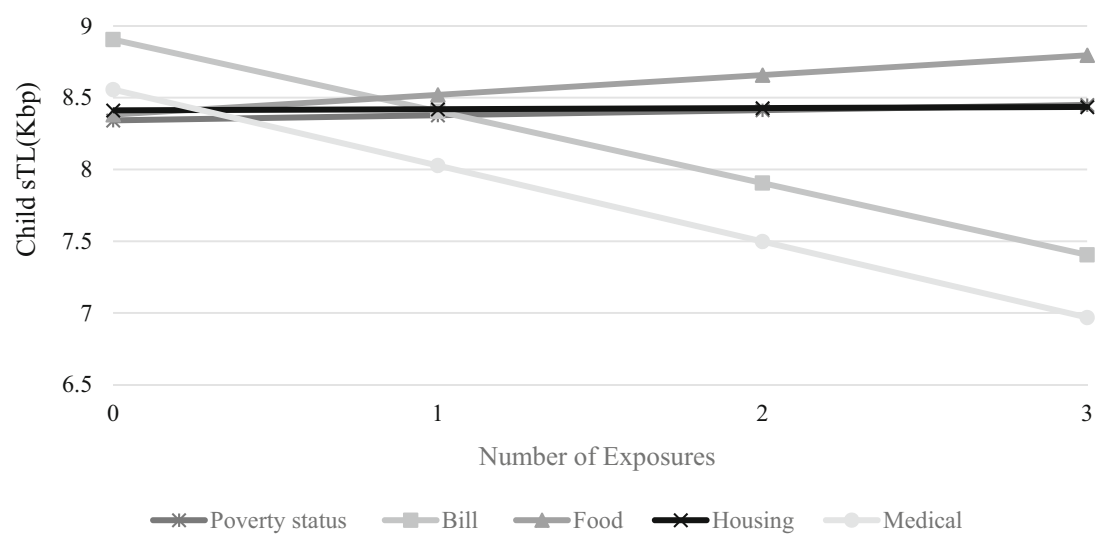

When examining relationships between different forms of material hardship and telomere length, the present study did, however, find that some forms of hardship were significantly related to premature cellular aging for Latina/o children. More specifically, greater exposure to bill and medical hardship was significantly related to shorter telomere length, whereas food insecurity and housing hardship did not play a significant role in premature cellular aging for Latina/o children at age 9. While this study only finds evidence that some measures of material hardship were significantly related to premature cellular aging, these findings align with a broader body of scholarship documenting the deleterious health consequences of material hardship [54-56, 63, 64] Moreover, given that material hardship measures are designed to assess various necessities for physical functioning (i.e., food, housing, medical care, and utilities), the findings from this study support a growing body of literature that suggests types of material hardship may be able to more accurately capture stressors associated with economic disadvantage.

The second objective of this study was to evaluate the extent to which parents' nativity explained economic disadvantagetelomere length patterns. Results from the regression analyses show minimal evidence parents' nativity that significantly played a role in economic disadvantage-telomere length patterns for Latina/o children. For example, of the five measures included, medical hardship was the only form of economic

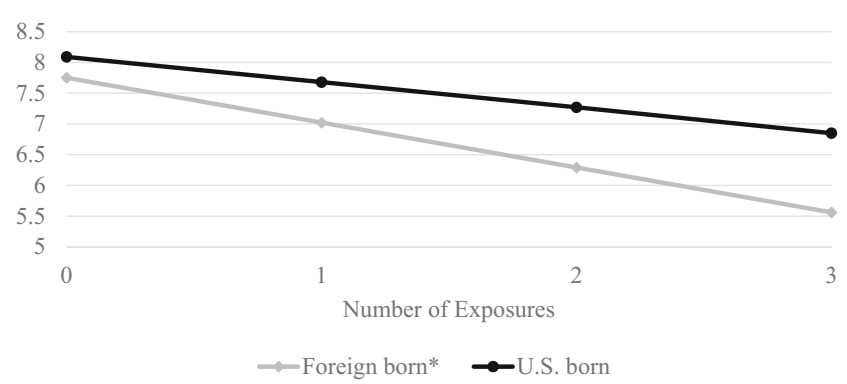

Fig. 2 Average TL and medical hardship by parent nativity. Note: Asterisk indicates that the trend (i.e., slope) is significantly different from zero at $\mathrm{p}<.05$ disadvantage shown to be significantly related to telomere length across parent nativity. More specifically, an increased number of reported exposures to medical hardship were associated with shorter telomere length for Latina/o children with at least one foreign-born parent. These findings align with literature that shows immigrant parents often have difficulty accessing health care for their children, even if their children are US citizens $[65,66]$. Prior research also suggests that even if access to care is available, foreign-born parents are generally less satisfied, report lower ratings of care, and are more likely to feel discriminated in health care settings [67-70]. As a result, it is plausible that the significant challenges and stressors associated with access and quality of care could explain the medical hardship-telomere length patterns observed for Latina/o children with at least one foreign-born parent.

The present study has several important limitations. First, studies demonstrate notable health inequities across Latina/o ethnic groups [70-74], but due to the relatively small subsample of Latina/os included in the FFCWS, I was unable to account for a number of sub-ethnic groups that fall underneath the pan-ethnic umbrella. Furthermore, given the design of the FFCWS, all children in the sample are US born. Therefore, the present study was unable to assess whether there were potential generational differences in the risk of premature cellular aging among Latina/o children. In terms of material hardship measures, the reliance on parents' self-reports may have led to underreporting of the number of hardships. Furthermore, the present study was unable to account for the duration of the hardship (i.e., days, weeks, months), which could potentially provide a more nuanced understanding of how the degree of stress exposure for both caregivers and children shapes telomere length patterns. Finally, this is the first study to examine relationships between measures of economic disadvantage and telomere length using a longitudinal sample of Latina/o children. As a result, replication of this study's findings is encouraged as the collection, and use of more racially and ethnically diverse samples that are longitudinal in nature become available. 
Even in the context of these limitations, findings from this study contribute to the small but growing body of literature attempting to understand the health consequences of economic deprivation for Latina/o children. In particular, findings from this study demonstrate that chronic exposure to some forms of material hardship increases the risk of premature cellular aging, which has the potential to shape morbidity and mortality outcomes later in life. Results from this study also suggest that material hardship, rather than traditional measures of income-based poverty, may better help us understand the physiological consequences of economic deprivation, particularly for Latina/o children.

Supplementary Information The online version contains supplementary material available at https://doi.org/10.1007/s40615-021-01072-x.

\section{Declarations}

Ethics Approval All procedures performed in studies involving human participants were in accordance with the ethical standards of the institutional and/or national research committee and with the 1964 Helsinki declaration and its later amendments or comparable ethical standards.

Informed Consent Informed consent was obtained from all individual participants included in the study.

Conflict of Interest The author declares no competing interests.

\section{References}

1. Murphey, D, Madill R, and Lina Guzman. Making math count more for young Latino children. Washington, DC: Child Trends. 2017. https://www.hsfoundation.org/wp-content/uploads/EarlyMath-Report-2.8.pdf. Accessed 1 March 2021.

2. Phelan JC, Link BG. Is racism a fundamental cause of inequalities in health? Annu Rev Sociol. 2015;41:311-30.

3. Child Trends Databank. Children in poverty. 2019. https://www. childtrends.org/?indicators=children-in-poverty. Accessed 1 March 2021.

4. Thomas, D, Richard F. Prior to COVID-19, child poverty rates had reached record lows in the U.S. Pew Research Center. 2020. Pew Research Center. https://www.pewresearch.org/fact-tank/2020/11/ 30/prior-to-covid-19-child-poverty-rates-had-reached-record-lowsin-u-s/. Accessed 1 March 2021.

5. Krogstad JM, Lopez MH. Coronavirus Economic Downturn Has Hit Latinos Especially Hard. Pew research Center. 2020;4. https:// www.pewresearch.org/hispanic/wp-content/uploads/sites/5/2020/ 08/PH_08.04.20_latino.economy.covid_Full.Report.pdf Accessed 4 March 2021.

6. Padilla, C, Thomson D. More than one in four Latino and Black households with children are experiencing three or more hardships during COVID-19. Child Trends. 2021. https://www.childtrends. org/publications/more-than-one-in-four-latino-and-blackhouseholds-with-children-are-experiencing-three-or-morehardships-during-covid-19. Accessed 4 March 2021.

7. Flores G, Brotanek J. The healthy immigrant effect: a greater understanding might help us improve the health of all children. Arch Pediatr Adolesc Med. 2005;159:295-7.
8. Lora KR, Giraud DW, Davy SR, Driskell JA. 2006. Children of Latino immigrants, 4-8 years, in rural Nebraska are adequate in vitamin B-6. Int J Vitam Nutr Res. 2006;76:47-56.

9. Mazur RE, Marquis GS, Jensen HH. Diet and food insufficiency among Hispanic youths: acculturation and socioeconomic factors in the third National Health and Nutrition Examination Survey. Am J Clin Nutr. 2003;78:1120-7.

10. Baker EH, Altman CE. Maternal ratings of child health and child obesity, variations by mother's race/ethnicity and nativity. Matern Child Health J. 2005;19:1000-9.

11. Schmeer KK. Early childhood economic disadvantage and the health of Hispanic children. Soc Sci Med. 2012;75:1523-30.

12. Hoeft KS, Barker JC, Masterson EE. Maternal beliefs and motivations for first dental visit by low-income Mexican American children in California. Pediatr Dent. 2011;33:392-8.

13. DeCamp LR, Bundy DG. Generational status, health insurance, and public benefit participation among low-income Latino children. Matern Child Health J. 2012;16:735-43.

14. Langellier BA, Chen J, Vargas-Bustamante A, Inkelas M, Ortega AN. Understanding healthcare access and utilization disparities among Latino children in the United States. J Child Health Care. 2016;20:133-44.

15. Robila M, Krishnakumar A. Economic pressure and children's psychological functioning. J Child Fam Stud. 2006;15:433-41.

16. Yoo JP, Slack KS, Holl JL. Material hardship and the physical health of school-aged children in low-income households. Am J Public Health. 2009;99:829-36.

17. Bradley RH, Corwyn RF. Socioeconomic status and child development. Annu Rev Psychol. 2002;53:371-99.

18. Conger RD, Donnellan MB. An interactionist perspective on the socioeconomic context of human development. Annu Rev Psychol. 2007;58:175-99.

19. Grant KE, Compas BE, Stuhlmacher AF, Thurm AE, McMahon SD, Halpert JA. Stressors and child and adolescent psychopathology: moving from markers to mechanisms of risk. Psychol Bull. 2003; 129:447-66.

20. Geronimus AT, Hicken M, Keene D, Bound J. "Weathering" and age patterns of allostatic load scores among Blacks and Whites in the United States." Am J Public Health 2006;96: 826-833.

21. McEwen BS. 1998. Protective and damaging effects of stress mediators. N Engl J Med. 1998;338:171-9.

22. Pearlin LI. The Sociological Study of Stress. J Health Soc Behav. 1989;30(3):241-56.

23. Geronimus AT. The weathering hypothesis and the health of African-American women and infants: evidence and speculations. Ethn Dis. 1992;2:207-21.

24. McEwen BS, Steller E. Stress and the individual: mechanism leafing to disease. Arch Intern Med. 1993;153:2093-101.

25. Beckie TM. A systematic review of allostatic load, health, and health disparities. Biol Res Nurs. 2012;14:311-46.

26. Juster RP, McEwen BS, Lupien SJ. Allostatic load biomarkers of chronic stress and impact on health and cognition. Neurosci Biobehav Rev. 2010:35.2-16.

27. Epel E.S. Telomeres in a life-span perspective: a new "psychobiomarker?. Curr Dir Psychol Sci 2009;18: 6-10

28. Tomiyama A, O'Donovan JA, Lin J, Puterman E, Lazaro A, Chan J, et al. Does cellular aging relate to patterns of allostasis?: An examination of basal and stress reactive HPA axis activity and telomere length. Physiol Behav. 2012;106:40-5.

29. Flannagan KS, Jansen EC, Rozek LS, Rentschler KM, Roman AV, Ramirez-Zea M, et al. Sociodemographic correlates and family aggregation of leukocyte telomere length in adults and children from Mesoamerica. Am J Hum Biol. 2017;29:1-16.

30. Wojcicki JM, Olveda R, Heyman MB, Elwan D, Lin J, Blackburn E, et al. Cord blood telomere length in Latino infants: relation with maternal education and infant sex. Am J Perinatol. 2016;36:235-41. 
31. Sanders JL, Fitzpatrick AL, Boudreau RM, Arnold AM, Aviv A, Kimura M, et al. Leukocyte telomere length is associated with noninvasively measured age-related disease: the cardiovascular health study. J Gerontol A. Biol Sci Med Sci. 2012;67:409-16.

32. Campisi J, Di Fagagna FD. Cellular Senescence: when bad things happen to good cells. Nat Rev Mol Cell Biol. 2007;8:729-40.

33. Cawthon RM, Smith KR, O'Brien E, Sivatchenko A, Kerber RA. Association between telomere length in blood and mortality in people aged 60 years or older. Lancet. 2003;361:393-5.

34. Epel ES, Lin J, Wilhelm FH, Wolkowitz OM, Cawthon R, Adler NE, et al. 2006. Cell aging in relation to stress arousal and cardiovascular disease risk factors. Psychoneuroendocrinology. 2006;31:277-87.

35. Fitzpatrick AL, Kronmal RA, Gardner JP, Psaty BM, Jenny NS, Tracy RP, et al. Leukocyte telomere length and cardiovascular disease in the cardiovascular health study. Am J Epidemiol. 2007;165(1):14-21.

36. Haycock PC, Heydon EE, Kaptoge S, Butterworth AS, Thompson A, Willeit P. Leucocyte telomere length and risk of cardiovascular disease: systematic review and meta-analysis. BMJ. 2014;349:1-14.

37. Rode L, Nordestgaard BG, Bojesen SE. Peripheral blood leukocyte telomere length and mortality among 64,637 individuals from the general population. J Natl Cancer Inst. 2015;107:1-8.

38. Mitchell C, Hobcraft J, McLanahan SS, Siegel SR, Berg A, BrooksGunn J, et al. 2014. Social disadvantage, genetic sensitivity, and children's telomere length. Proc Natl Acad Sci. 2014;111:5944-9.

39. Enlow MB, Kane-Grade F, De Vivo I, Petty CR, Nelson CA. Patterns of change in telomere length over the first three years of life in healthy children. Psychoneuroendocrinology. 2020;115:1-9.

40. James S, McLanahan S, Brooks-Gunn J, Mitchell C, Schneper L, Wagner B, et al. 2017. Sleep duration and telomere length in children. J Pediatr. 2017;187:247-52.

41. Massey DS, Wagner B, Donnelly L, McLanahan S, Brooks-Gunn J, Garfinkel I, et al. 2018. Neighborhood disadvantage and telomere length: results from the fragile families study. RSF. 2018;4:28-42.

42. Needham BL, Adler N, Gregorich S, Rehkopf D, Lin J, Blackburn $\mathrm{EH}$, et al. 2013. Socioeconomic status, health behavior, and leukocyte telomere length in the National Health and Nutrition Examination Survey, 1999-2002. Soc Sci Med. 2013;85:1-8.

43. Diaz CJ, Koning SM, Martinez-Donate AP. Moving beyond salmon bias: Mexican return migration and health selection. Demography. 2016;53:2005-30.

44. Diaz CJ, Niño M. Familism and the Hispanic health advantage: the role of immigrant status. J Health Soc Behav. 2019;60:274-90.

45. Velasco-Mondragon E, Jimenez A, Palladino-Davis AG, Davis D, Escamilla-Cejudo JA. Hispanic health in the USA: a scoping review of the literature. Public Health Rev. 2016;37:1-27.

46. Hamilton ER, Cardoso JB, Hummer RA, Padilla YC. Assimilation and emerging health disparities among new generations of U.S. children. Demogr Res. 2011;25:783-818.

47. Hummer RA, Powers DA, Pullum SG, Gossman GL, Frisbie WP. Paradox found (again): infant mortality among the Mexican-origin population in the United States. Demography. 2007;2007(44):441-57.

48. Boudreau ADA, Kurowski DS, Gonzalez WI, Dimond MA, Oreskovic NM. 2013. Latino families, primary care, and childhood obesity: a randomized controlled trial. Am J Prev Med. 2013;44:S247-57.

49. Flores G, Fuentes-Afflick E, Barbot O, Carter-Pokras O, Claudio L, Lara M, et al. The health of Latino children: urgent priorities, unanswered questions, and a research agenda. JAMA. 2002;2002(288):82-90.

50. Gesell SB, Reynolds EB, Ip EH, Fenlason LC, Pont SJ, Poe EK, et al. Social influences on self-reported physical activity in overweight Latino children. Clin Exp Pediatr. 2008;47:797-802.

51. Calado RT, Young NS. Telomere Diseases. N Engl J Med. 2009;36:2353-65.
52. Epel ES, Blackburn EH, Lin J, Dhabhar FS, Adler NE, Morrow JD, et al. 2004. Accelerated telomere shortening in response to life stress. Proc Natl Acad Sci. 2004;101:17312-5.

53. Fitzpatrick AL, Kronmal RA, Kimura M, Gardner JP, Psaty BM, Jenny NS, et al. Leukocyte telomere length and mortality in the Cardiovascular Health Study. J Gerontol A-Biol. 2011;66:421-9.

54. Donni PL. The unobserved pattern of material hardship and health among older Americans. J Health Econ. 2019;65:31-42.

55. Neckerman KM, Garfinkel I, Teitler JO, Waldfogel J, Wimer C. 2016. Beyond income poverty: measuring disadvantage in terms of material hardship and health. Acad Pediatr. 2016;16:S52-9.

56. Yoo JP, Slack KS, Holl JL. Material hardship and the physical health of school-aged children in low-income households. Am J Public Health. 2009;99:829-36.

57. Heflin C, Sandberg J, Rafail P. The structure of material hardship in US households: an examination of the coherence behind common measures of well-being. Soc Probl. 2009;56:746-64.

58. Carlson BL. Fragile families \& Child Wellbeing Study: Methodology for constructing mother, father, and couple weights for core telephone public survey data waves $1-4$. Mathematica Policy Research: 1-43.

59. Cochran WG. Sampling techniques. New Jersey: John Wiley \& Sons; 2007.

60. Orshansky M. How poverty is measured. Monthly Lab Rev. 1969;1969(92):37.

61. Mayer SE, Christopher J. Poverty and the distribution of material hardship. J Hum Resour. 1989;24:88-114.

62. Rector RE, Kirk AJ, Youssef SE. The extent of material hardship and poverty in the United States. Rev Soc Econ. 1999;53:351-87.

63. Desmond M, Kimbro RT. 2015. Eviction's fallout: housing, hardship, and health. Soc Forces. 2015;94:295-324.

64. Huang Y, Heflin CM, Validova A. 2021. Material hardship, perceived stress, and health in early adulthood. Ann Epidemiol. 2021;53:69-75.

65. Cervantes AG, Menjívar C. Legal violence, health, and access to care: Latina immigrants in rural and urban Kansas. J Health Soc Behav. 2020;61(3):307-23.

66. Gelatt J. Immigration status and the healthcare access and health of children of immigrants. Soc Sci Q. 2016;97:540-54.

67. Calvo R, Hawkins SS. Disparities in quality of healthcare of children from immigrant families in the U.S. Matern Child Health J. 2015;19:2223-32.

68. Castañeda H, Holmes SM, Madrigal DS, Young MED, Beyeler N, Quesada J. Immigration as a social determinant of health. Annu Rev Public Health. 2015;36:375-92.

69. Pitkin DK, Bahney BW, Lurie N, Escarce JJ. 2009. Immigrants and health care access, quality, and cost. Med Care Res Rev. 2009;66:355408.

70. Karoly LA, Gonzalez GC. Early care and education for children in immigrant families. Futur Child. 2011;21:71-101.

71. Kimbro RT, Gorman BK, Schachter A. Acculturation and self-rated health among Latino and Asian immigrants to the United States. Soc Probl. 2012;59:341-63.

72. Velasco-Mondragon E, Jimenez A, Palladino-Davis AG, Davis D, Escamilla-Cejudo JA. Hispanic health in the USA: a scoping review of the literature. Public Health Rev. 2016;37:1-27.

73. Zsembik BA, Fennell D. Ethnic variation in health and the determinants of health among Latinos. Soc Sci Med. 2005;61:53-63.

74. Perrin JM, MacLean WE, Perrin EC. Parental perceptions of health status and psychologic adjustment of children with asthma. Pediatrics. 1989;83:26-30.

Publisher's Note Springer Nature remains neutral with regard to jurisdictional claims in published maps and institutional affiliations. 